\title{
CHILDHOOD CONSTIPATION AND ITS MANAGEMENT
}

\author{
Carla Porter, SHO, Paediatrics \\ Royal Lancaster Infirmary
}

Constipation in childhood is a common problem facing both paediatricians and general practitioners. It features amongst the top ten referrals to paediatric outpatients. The commonest age group at presentation is between one and five years but it can present at any age.

\section{DEFINITION}

Constipation is the painful passage of hard, infrequent stools, in general less than three times per week.

It is important to know the normal range. Formula-fed infants pass, on average, three or four stools per day. The frequency in breast-fed babies varies tremendously, ranging from one small soft-formed stool per week to twelve or more watery stools per day.

Toddlers and young children vary from one every other day to two or three stools per day.

In addition to delay and difficulty in the passage of stools some children can have faecal soiling as a result of overflow of faecal fluid or semi-solid stools around a loaded rectum, with the child being unable to control the soiling. If the treatment of constipation is delayed then changes including megarectum and megacolon can occur, where the rectum and colon can become overdistended with faeces. This leads to loss of the normal sensation of 'the need to pass stool', which can result in 'soiling' of large volumes of stool.

\section{AETIOLOGY}

The causes are wide-ranging, often multifactorial, and include the following:

- physical: cerebral palsy, spinal injuries, Hirschsprung's and coeliac disease

- metabolic: hypothyroidism, hypercalceamia

- acute illness: any acute illness, especially if fever present

- diet and fluids: poor dietary fibre intake, poor water-based fluid intake, excess milk in toddlers

- medications: eg diuretics and analgesics

- psychological: fear of toileting/passing painful stools/ school toilets

- other: family history of constipation.

\section{HISTORY}

The importance of a good history cannot be over-emphasised in managing children with constipation. Listed below are some questions that should be asked.
- was there delayed passage of meconium at birth?

- at what age and following which circumstances did the problem start?

- what is and was the child's normal bowel pattern?

- was there an acute illness that may have precipitated it?

- how is the child's general health?

- is the child on any medication or supplements?

- what are the child's stools like - colour, smell, consistency?

- does the child pass flatus? Is it excessive or particularly smelly?

- what is the child's typical diet and fluid intake? Go through a precise 24-hour intake

- does the child use the potty or toilet?

- is there a history of soiling or encopresis?

- is there a positive family history?

\section{SYMPTOMS AND SIGNS}

The following may be present:

- poor appetite

- lack of energy

- mood changes - unhappiness, irritability, anger

- irregular bowel habit

- passage of large stools on an infrequent basis

- smelly flatus and stools

- stools with irregular texture

- withholding or straining to stop stools

- pain on passage of stools

- enuresis and urinary tract infections

- failure to thrive.

This is clearly not an exhaustive list, but shows that children with constipation can present in a variety of ways, not just noticeable delay in passing stools or abdominal discomfort.

\section{EXAMINATION}

This should include a full systematic examination looking for any signs or features of underlying organic pathology. Careful examination of the abdomen may reveal distension, tenderness and possible faecal loading. The perianal area 
should be examined looking for tears, infection, fissure and tags.

\section{A rectal examination should not be performed.}

This is a traumatic experience for any child and rarely provides useful information.

\section{INVESTIGATIONS}

It is unusual for these to be necessary, unless there is concern about organic pathology.

\section{MANAGEMENT}

This is often not easy, requiring different treatment at different stages, sometimes over long periods of time and possibly requiring multiple laxatives at any one time. The evidence base for the treatment of constipation is only really secure at the level of expert opinion and clinical practice, as there are very few randomised control trials in the medical literature.

In general there are four principles in the management of constipation:

1 Diet, fluids and exercise - the importance of these cannot be over-emphasised

2 Softening of any retained stool

3 Evacuation of retained stool

4 Maintenance therapy.

The common reasons for laxatives not working are either non-compliance with medication or that they are given in an incorrect order and at an incorrect stage.

\section{Categories of laxatives}

Stimulants: these act by increasing intestinal motility and include senna, bisacodyl, sodium picosulphate and docusate.

Softeners: these are osmotic agents, acting mainly by drawing water into the bowel. They include lactulose and movicol.

A review of clinical experience and best practice papers ${ }^{(1-3)}$ has allowed a general consensus review and approach to the management of constipation in the different stages as outlined below.

\section{Stage one - diet, fluids and exercise}

The importance of a good diet and plentiful fluid intake is vital in the initial management and maintenance treatment of constipation. Exercise in children is also important to emphasise.

All children who are being treated for constipation should have a discussion and be provided with written information on diet, fluids and exercise. Ideally water or water-based cordials should be given. Excessive milk and dairy products are a common cause for constipation and must be asked about specifically. A healthy child on a normal diet does not need more than half a pint of milk per day, with regular cheese and yoghurt.

\section{Stage two - softening of any retained stools}

The clinical experience and best practice papers recommend the use of four laxatives in the initial stages:
- lactulose

- movicol

- senna

- docusate.

The general consensus is to start with an initial osmotic agent, for example lactulose, and then a couple of days later to add in a stimulant, such as senna. The recommendations suggest that lactulose and senna be used initially over the other laxatives. (See below for movicol.)

\section{Stage three - disimpaction of retained stools}

This stage is not always necessary if the initial softening stage has worked well. However, for those children where the passage of stools is still a problem after initial treatment then slightly more aggressive therapy may be needed. Best practice recommendations for this stage include:

- senna

- sodium picosulphate

- movicol.

Sometimes combination therapy may be needed.

\section{Stage four - maintenance therapy}

This stage is required for months, and sometimes years, in some children and is necessary to ensure that regular stools are being passed, ideally aiming for more than three stools per week without discomfort.

Recommendations for laxatives in this stage include:

- lactulose

- senna

- bisacodyl

- sodium picosulphate

- movicol.

Again the general consensus from best practice recommendations is to use lactulose and senna for maintenance if at all possible.

\section{Movicol}

'Movicol Paediatric plain' is being used increasingly in our hospital for all stages of constipation management, following its success in the tertiary centres. It is an inert polymer of ethylene glycol which is an osmotic laxative. It works by absorbing water which has been drunk, but does not draw further fluid from the body into the bowel. It is therefore essential that it be taken with lots of water. The practitioner prescribing it must determine the 'stage' of constipation and prescribe the appropriate dose, explaining to parents and child that this will need adjusting either up or down as the child moves through the stages. Information on fluids, five pieces of fruit per day, exercise, post-prandial toilet visits and diary-keeping applies as with traditional laxatives and stimulants.

Movicol is a white powder, each sachet having to be mixed in a quarter of a glass of water. The recommended 'disimpaction' dose begins at 2-4 sachets per day, gradually increasing every couple of days to a maximum of 8-12 sachets per day until clearance is achieved. The dose is then reduced to a 'maintenance' level, usually 2-4 sachets per day.

To improve its effectiveness, it is essential that extra fluids are taken throughout the day -1.5 litres (6-8 glasses) is a 
good guide. Norgine, the manufacturers, produce a helpful Patient Record Card with appropriate dosages, helpful hints, diary and a wonderful 'Stool Form Scale', which is reproduced here.

\begin{tabular}{|c|c|}
\hline Type 1 & $\begin{array}{l}\text { Separate hard } \\
\text { lumps, like nuts } \\
\text { (hard to pass) }\end{array}$ \\
\hline Type 2 & $\begin{array}{c}\text { Sausage-shaped } \\
\text { but lumpy }\end{array}$ \\
\hline Type 3 & $\begin{array}{l}\text { Like a sausage } \\
\text { but with } \\
\text { cracks on its } \\
\text { surface }\end{array}$ \\
\hline Type 4 & $\begin{array}{l}\text { Like a sausage } \\
\text { or snake, } \\
\text { smooth and } \\
\text { soft }\end{array}$ \\
\hline Type 5 & $\begin{array}{l}\text { Soft blobs with } \\
\text { clear-cut edges } \\
\text { (passed easily) }\end{array}$ \\
\hline Type 6 & $\begin{array}{c}\text { Fluffy pieces } \\
\text { with ragged edges } \\
\text { a mushy stool }\end{array}$ \\
\hline Type 7 & $\begin{array}{l}\text { Watery, } \\
\text { no solid pieces } \\
\text { ENTIRELY } \\
\text { LIQUID }\end{array}$ \\
\hline
\end{tabular}

The Bristol Stool Form Scale

\section{INFANTS AND TODDLERS}

This group of patients can be particularly difficult to treat. Stimulant laxatives should generally be avoided. However, softeners - mainly lactulose - can be used. Sometimes slight modifications in diet are all that is needed with a reduction in milk intake substituted by water.

\section{GENERAL ADVICE}

The importance of diet, fluids, exercise and medication must be carefully explained and stressed to both the child and parents. Star charts as both documentation and reward are helpful to aid management. Consistent post-prandial visits to the toilet for ten minutes should be encouraged. A stool diary is a 'must'.

It is helpful to enlist the support of other health professionals, for example health visitor, school nurse, dietician and psychologist. However, it is essential that advice be consistent.

The use of enemas should be avoided unless absolutely necessary. If the treatment stages are followed and appropriate doses of laxatives used then they should not be needed.

The management of constipation can certainly be a difficult one. The guidelines above are based on expert clinical experience and best practice. It is hoped that they will provide a useful guide and adjunct to the management in children.

\section{REFERENCES}

1 Clayden G. Management of chronic constipation. Arch Dis Child 1992;67(3):340-44

2 Clayden G. Management of childhood constipation. Postgrad Med J 2003;79(937):616-21

3 Candy DCA, Edwards D. Management of chronic constipation. Current Paediatrics 2003;13(2):101-106

\section{OBESITY - A WIDESPREAD PROBLEM}

- Childhood obesity is now considered to be a global epidemic. It is defined as a BMI (weight in $\mathrm{kg}$ divided by height in metres $^{2}$ ) over 30 , or alternatively a BMI over 98 th centile.

- It is a medical and social problem, caused by a diet too high in fat and sugars, with insufficient physical exercise.

- It causes Type II diabetes, sleep apnoea, hypertension and psychological problems in childhood.

- Obese children become obese adults, with additional problems of coronary artery disease, osteoarthritis, fatty liver and polycystic ovary syndrome.
- An underlying medical cause is unlikely, but must be considered if the child is of short stature.

- Refer if associated medical problem, short stature, below 24 months of age or BMI over 99.6th centile.

- WHO recommends that the government should cut down on TV advertising of fattening food, create high tax on high fat and sugar foods, and turn school vending machines into scrap metal .

- Management is to promote lifestyle changes, to encourage healthy eating and reduce sedentary activity.

- Maintenance of weight, rather than weight reduction should be the goal. 